\title{
Effect of biological maturation on gross motor coordination in boys: a mediation analysis
}

\section{Efeito da maturação biológica sobre a coordenação motora grossa em meninos: uma análise de mediação}

\author{
Douglas Henrique Bezerra-Santos ${ }^{[a, b]} \mathbb{( D}$, Leonardo Gomes de Oliveira Luz ${ }^{[a, c]} \mathbb{D}$, Braulio Patrick da Silva- \\ Lima $^{[a, b]} \mathbb{( D}$, Ingrid Kelly Alves dos Santos-Pinheiro ${ }^{[a]} \mathbb{D}$, Arnaldo Tenório da Cunha-Júnior ${ }^{[a]} \mathbb{D}$, Humberto \\ Jefferson de Medeiros ${ }^{[a, b]}$
}

[a] Kinanthropometry, Physical Activity and Health Promotion Laboratory (LACAPS), Universidade Federal de Alagoas (UFAL), Arapiraca, AL, Brazil

${ }^{[b]}$ Graduate Program in Health and Society, Department of Physical Education, Universidade do Estado do Rio Grande do Norte (UERN), Mossoró, Brazil

${ }^{[c]}$ Research Unit for Sport and Physical Activity (CIDAF), Universidade de Coimbra (UC), Coimbra, Portugal

\begin{abstract}
Introduction: The literature emphasizes the importance of acquiring good motor coordination in the early years of life and its relationship with physical fitness and physical activity during adolescence and adulthood. Objective: To analyze the effect of biological maturation on the motor coordination in boys. Method: The sample was composed by 203 boys between 11 and 14 years old. Height, body mass, sitting height, waist circumference (WC) and skinfolds were measured. Somatic maturation (SM) was assessed by maturity offset (estimated age at peak height velocity). The gross motor coordination was evaluated by Körperkoordinationstest für Kinder (KTK) battery. Results: The SM exerted an effect on the walking
\end{abstract}

*DHBS: MS, e-mail: douglashenrique2102@hotmail.com

LGOL: PhD, e-mail: leonardoluz.ufal@gmail.com

BPSL: MS, e-mail: braulio_patrick@hotmail.com

IKASP: MS, e-mail: ingridk03@hotmail.com

ATCJ: PhD, e-mail: arnou555@hotmail.com

HJM: PhD, e-mail: hjmbeto@gmail.com 
backward on balance beams (WB) mediated by the WC. Conclusion: The results showed that the performance of boys in the WB was negatively influenced by the greater volume of fat in the trunk related to a more advanced state of SM.

Keywords: Anthropometry. Children. Motor Skills. Maturation.

\section{Resumo}

Introdução: A literatura enfatiza a importância da aquisição de uma boa coordenação motora nos anos iniciais da vida e sua relação com a aptidão física e a atividade física durante a adolescência e na fase adulta. Objetivo: Analisar o efeito da maturação biológica sobre o desempenho coordenativo de meninos. Método: A amostra contou com 203 meninos entre 11 e 14 anos. Foram medidos estatura, massa corporal, altura sentado, perímetro de cintura (PC) e dobras cutâneas. A maturação somática (MS) foi avaliada pelo maturity offset (estimativa da idade no pico de velocidade de crescimento). 0 Körperkoordinationstest für Kinder (KTK) foi o teste de coordenação motora utilizado (composto por 4 tarefas). Resultados: A MS exerceu efeito sobre o equilíbrio à retaguarda (ER), mediado pelo PC. Conclusão: Conclui-se que o desempenho dos meninos no ER sofre efeito negativo do maior acúmulo de gordura no tronco relacionado a um estado mais avançado de MS.

Palavras-chave: Antropometria. Crianças. Destreza Motora. Maturação.

\section{Introduction}

The literature emphasizes the importance of acquiring good motor coordination in the early years of life and its relationship with physical fitness and physical activity during adolescence and adulthood $[1,2]$. It is believed that the proper interpretation of coordinative performance is crucial for adherence and maintenance in sports and physical exercise in children and young people. In this sense, the Körperkoordinationstest für Kinder (KTK) has been one of the instruments chosen by the world literature [3] to assess motor coordination. In a recent systematic review, livonen et al. [4] stated that the largest volume of studies reported associations of KTK performance with other health-related factors. Of these associative studies, most investigated biological factors. Studies have often focused on the association with body composition, physical activity or physical fitness of children, which could be expected in view of the global concern with the tendency to increase weight status and physical inactivity among young people [5].

Luz et al. [6] showed that, in both sexes, subjects with delayed maturation status had lower body mass, less fat and fat-free mass and better scores in KTK tasks in relation to their peers classified as advanced. These results confirmed the trend found in the literature that the most advanced subjects in the maturational aspect have disadvantage in motor coordination tests, specifically in the KTK battery [7 - 9].

In a study with children of both sexes, Lopes et al. [10] stated that, among a set of anthropometric variables, the increased value of the waist circumference was the one that stood out the most in the association with poor performance in KTK in boys. For girls, on the other hand, the percentage of fat showed greater sensitivity to predict low motor coordination. D'Hondt et al. [11] also stated that there is an inverse relationship between body adiposity and performance in KTK tasks, however they attributed this evidence to subjects with more advanced age. A possible explanation for such findings may be that children's motor development increases as they become more mature. However, the more advanced the individual's biological maturation tends to be, this increase tends to be slower and stabilize [12]. On the other hand, weight gain, which is also related to maturation, tends to increase, which would contribute to a greater chance of having an inversely proportional association between body adiposity and KTK performance in young people with more advanced maturation status.

In this context, Luz et al. [13], in a study conducted with prepubescent boys, through correlations and 
mediation analysis, found an inverse association between the maturational state and the walking backward task of the KTK, with a total mediation of $77 \%$ of waist circumference. However, there appears to be a gap in the literature for approaches of this type with individuals at puberty. In fact, the present study aimed to: 1) verify the relationship between biological maturation and isolated performance in KTK tasks in young men of pubertal age and 2) examine whether the association between biological maturation and performance in KTK is mediated by some anthropometric variable of the individuals.

\section{Method}

\section{Participants}

This is a cross-sectional, descriptive empirical research carried out with students enrolled in public schools in the urban area of the city of Arapiraca, Alagoas. The study was planned and conducted in compliance with international standards for experimentation with humans (Declaration of Helsinki, 1975) [14] and duly approved by the Research Ethics Committee of Federal University of Alagoas (UFAL), whose acceptance number (CAAE) is 50352015.9. 0000.5013. Schools were selected by stratified criteria (by region of the urban area) and the participants were chosen by non-probability sampling for accessibility.

The sample consisted of 203 young men aged between 11 and 14 years. All individuals enrolled in elementary school II were recruited and delivered the Free and Informed Consent Form (FICF), signed personally and by the guardians of education. Failure to deliver the informed consent form, absence on the day of data collection or physical disability to perform the tasks of the KTK were defined as an exclusion criteria.

\section{Procedures}

\section{Anthropometry}

The anthropometric variables evaluated were body mass, height, sitting height, waist circumference and skinfolds. To assess body mass, the subject was asked to assume the standing position on the scale, in an orthostatic position, relaxed shoulders and arms loose at the sides. The measurement was taken using a digital scale
(Techline, São Paulo, Brazil), accurate to 100 grams. Height, sitting height and waist circumference were measured by an anthropometric steel measuring tape (Sanny Medical Starrett, São Paulo, Brazil) with $0.1 \mathrm{~cm}$ precision. Sitting height and height were measured after maximal inspiration, with the measuring tape attached to the wall. The waist circumference was measured at the midpoint between the last costal arch and the iliac crest, at the moment of minimum breathing. The triceps and subscapular skinfolds were measured with a Lange adipometer, with a precision of $1 \mathrm{~mm}$ (Beta Technology, Santa Cruz, California, USA), from an average of three measurements collected at each pre-established anatomical point, in a rotational order. The procedures used were based on the instructions recommended by Lohman et al. [15]. From the simple measurements, the Body Mass Index (BMI), the length of the lower limbs (height - sitting height) and the sum of the skinfolds were calculated.

\section{Biological Maturation}

The estimated age at the Peak Height Velocity (PHV) was used to assess somatic maturation. For this, the maturity offset calculation method proposed by Mirwald et al. [16]. The method considers for estimating maturity offset the following variables: chronological age, body mass, height, sitting height and length of the lower limbs. The same procedure was used in studies with samples similar to the present study $[17,18]$.

\section{Motor Coordination}

To measure gross motor coordination, the German test KTK, proposed by Kiphard and Schilling [19], was used. The test consists of four tasks, Walking Backward (WB), Jumping Sideways (JS), Moving Sideways (MS) and Hopping for Height (HH). The psychometric characteristics of the KTK point to a test-retest reliability coefficient for each task, separately, which task varies between 0.80 and 0.96 [19]. For analysis purposes, the raw scores for each KTK task were used, as also used by Bigoni et al. [20] and Luz et al. [21].

\section{Statistical analysis}

Descriptive data analysis was performed, and normality was tested using the Kolmogorov-Smirnov test and visual inspection of the histogram. In sequence, the partial correlation test was performed, with 
chronological age as a covariate, between the anthropometric variables (height, body mass, BMI, sitting height, waist circumference and the sum of the triceps and subscapular skinfolds), the value maturity offset and the scores for each KTK task. Finally, linear regression models adjusted for chronological age, were performed with the aim of examining how much of the relationship between maturation status and KTK performance was mediated by anthropometric characteristics [22]. The procedures suggested by Baron and Kenny [22], as well as the criteria adopted to establish the mediating effect of some variable, are described in previous studies [13, 23]. Significance of $p<0.05$ was adopted in analyzes performed. The IBM SPSS 22.0 software (SPSS, Inc., Chicago, IL) was used.

\section{Results}

Table 1 illustrates the descriptive results of the study variables for the total sample. Participants have a height variation of 131.0 to $181.0 \mathrm{~cm}$ and body mass from 25.6 to $79.9 \mathrm{~kg}$. The average age is 13.13 years and the average age at peak height velocity is estimated at 14.40 years.

Table 1 - Descriptive statistics (range, mean value including 95\% Confidence Limits (CL) of the mean, and Standard Deviation (SD) for the total sample of school adolescents $(\mathrm{N}=203)$

\begin{tabular}{lccccc}
\hline Variables & \multicolumn{2}{c}{ Range } & \multicolumn{2}{c}{ Mean } & Standard \\
& Min & Max & Value & $\mathbf{( 9 5 \% C L )}$ & deviation \\
\hline Chronological age (year) & 11.05 & 14.88 & 13.13 & $(12.99 ; 13.28)$ & 1.05 \\
Estimated age at PHV (year) & 12.86 & 15.81 & 14.40 & $(14.32 ; 14.49)$ & 0.62 \\
Maturity offset (year) & -3.60 & 1.60 & -1.27 & $(-1.42 ;-1.11)$ & 1.14 \\
Height (cm) & 131.0 & 181.0 & 158.2 & $(156.7 ; 159.7)$ & 10.9 \\
Body mass (kg) & 25.6 & 79.9 & 48.5 & $(46.9 ; 50.0)$ & 11.3 \\
BMl (kg.m²) & 13.2 & 27.7 & 19.2 & $(18.7 ; 19.5)$ & 3.0 \\
Sitting height (cm) & 64.0 & 93.0 & 77.2 & $(76.3 ; 78.0)$ & 6.1 \\
Waist circumference (cm) & 54.0 & 81.0 & 66.1 & $(65.3 ; 67.0)$ & 6.3 \\
Sum of Skinfolds* (mm) & 14 & 55 & 29.4 & $(28.2 ; 30.6)$ & 8.9 \\
Walking Backward (\#) & 15 & 72 & 53.9 & $(52.3 ; 55.6)$ & 11.8 \\
Jumping sideways (\#) & 13 & 92 & 57.5 & $(55.6 ; 59.3)$ & 13.6 \\
Moving sideways (\#) & 22 & 66 & 42.0 & $(40.8 ; 43.1)$ & 8.0 \\
Hopping for height (\#) & 18 & 76 & 57.6 & $(55.9 ; 59.2)$ & 11.9 \\
\hline
\end{tabular}

Note: 95\% CL (95\% Confidence Limits); PHV (Peak Height Velocity); BMI (Body Mass Index); *Sum of triciptal and subscapular skinfolds; \# (no measurement unit). Source: The authors (2020).

Table 2 shows the partial correlation coefficients between anthropometric variables, biological maturity offset (maturity offset) and performance in each KTK task, with chronological age as a covariate. The results showed a positive and significant correlation between all anthropometric variables and biological maturation. Among the tasks of the KTK, the only one that was related to biological maturation was the task of WB $(r=-0.20$; $p$ $<0.05$ ). This KTK task was also shown to be related to anthropometric variables, except for sitting height(Figure 1).

Table 2 - Partial correlation coefficients between anthropometric variables, biological maturation and performance on motor coordination tests (KTK) controlled by chronological age

\begin{tabular}{lccccc}
\hline \multirow{2}{*}{ Variables } & Maturity offset & \multicolumn{3}{c}{ KTK } \\
\cline { 3 - 6 } & & $\begin{array}{c}\text { Walking } \\
\text { Backward (WB) }\end{array}$ & $\begin{array}{c}\text { Jumping } \\
\text { Sideways (JS) }\end{array}$ & $\begin{array}{c}\text { Moving } \\
\text { Sideways (MS) }\end{array}$ & $\begin{array}{c}\text { Hopping for } \\
\text { Heigh (HH) }\end{array}$ \\
\hline Height & $0.80^{*}$ & $-0.18^{*}$ & -0.01 & -0.05 & 0.01 \\
Body mass & $0.75^{*}$ & $-0.23^{*}$ & -0.01 & -0.10 & $-0.15^{*}$ \\
BMl & $0.49^{*}$ & $-0.21^{*}$ & -0.01 & -0.10 & $-0.19^{*}$ \\
Sitting height & $0.98^{*}$ & -0.19 & -0.06 & -0.01 & 0.01 \\
Waist circumference & $0.59^{*}$ & $-0.28^{*}$ & -0.06 & -0.13 & $-0.25^{*}$ \\
Sum of Skinfolds** & $0.44^{*}$ & $-0.20^{*}$ & -0.02 & -0.12 & $-0.27^{*}$ \\
Maturity offset & - & $-0.20^{*}$ & 0.06 & -0.03 & -0.02 \\
\hline
\end{tabular}

Note: BMI (Body Mass Index); ${ }^{*}$ Sum of triciptal and subscapular skinfolds; ${ }^{*} p<0.05$. Source: The authors (2020). 


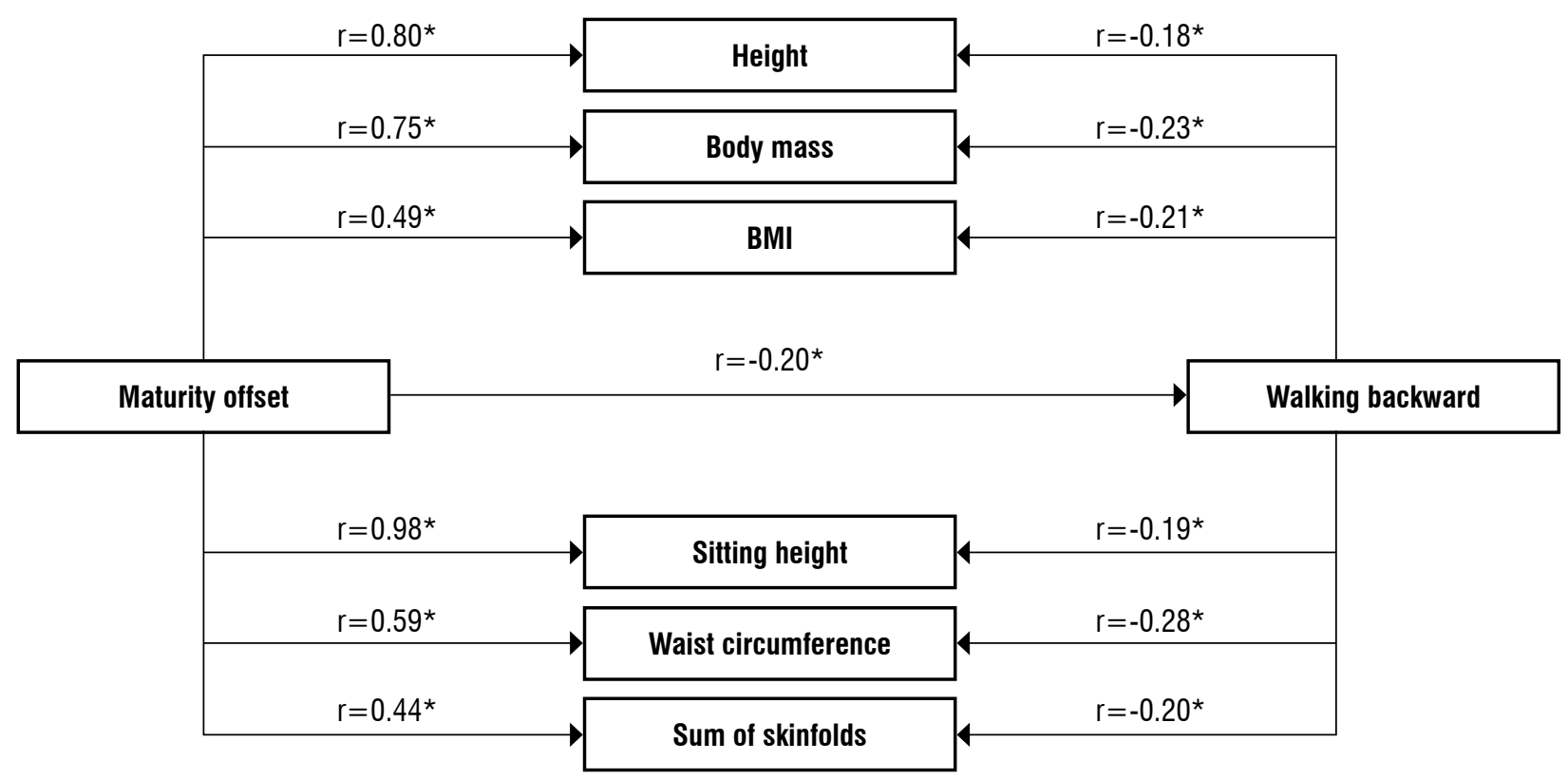

Figure 1 - Partial correlation coefficients between anthropometric variables, biological maturation and Walking Backward (WB) controlled by chronological age.

Note: BMI (Body Mass Index); Sum of skinfolds (triciptal and subscapular skinfolds); ${ }^{\star} p<0.05$. Source: The authors (2020).

Figure 2 shows that among all the anthropometric variables significantly associated with the task of walking backward of the KTK, the waist circumference was the only one that presented itself as a total mediator of the relationship between biological maturation and test performance (mediation of $72 \%$ ).
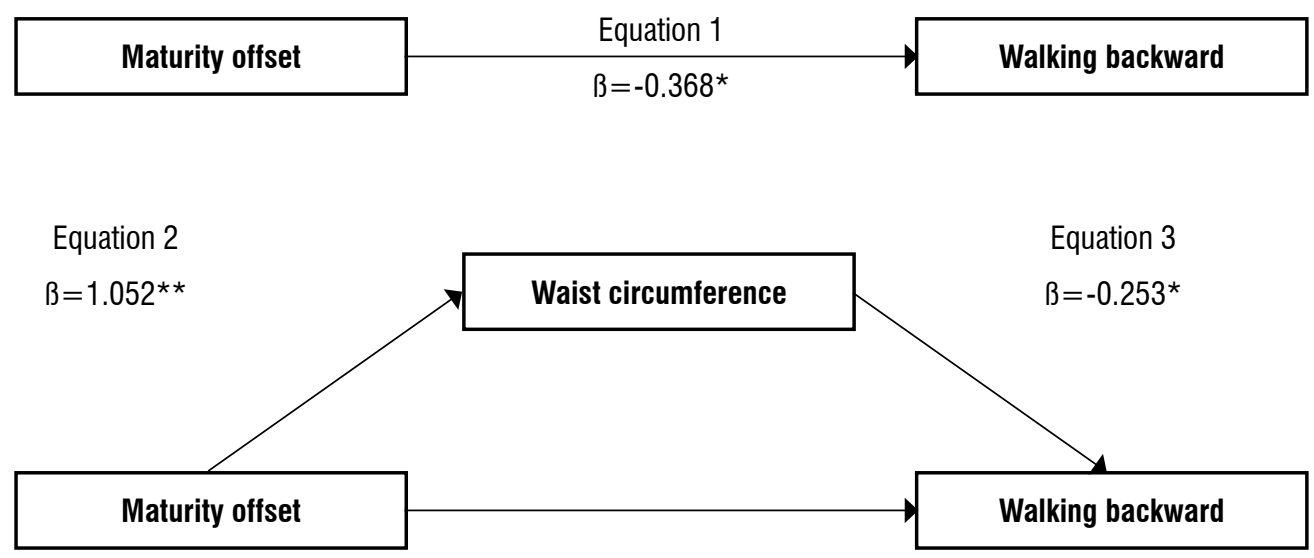

Equation 3

$B=-0.102$

Figure 2 - Mediation model of the relationship between biological maturation and Walking Backward (WB) after adjustment for chronological age.

Note: ${ }^{*} p<0.01 ;{ }^{* *} p<0.001$. Source: The authors (2020). 


\section{Discussion}

The present study verified the association between biological maturation, anthropometric variables and KTK tasks, which had their scores analyzed separately, in male students, aged between 11.05 and 14.88 years, whose average age at the peak height rate was estimated at 14.40 years. The results showed that individuals more advanced in biological maturation are taller, heavier, in addition to having higher BMI values, greater sum of skinfolds and greater waist circumference in relation to their less advanced peers. Walking balance and $\mathrm{HH}$ were inversely associated with anthropometric variables, which it is believed that less burly individuals have advantages in performing these KTK tasks. Biological maturation was significantly associated with the task of WB, with the most advanced subjects being those with the worst scores in this task, an effect mediated by the greater accumulation of fat in the waist region, characteristic of a more advanced maturational state in boys.

In the last 10 years, among the studies published with the KTK, the works that aimed to analyze the association between performance in their tasks and the BMI of children and young people stood out, due to their pioneering spirit and greater number of publications, either in cross-sectional [11, 24, 25], longitudinal [26], as well as, in systematic review with meta-analysis [27]. The evidence showed that overweight and obese individuals had worse KTK performances compared to their normal weight peers. The results of the present study confirmed the evidence in the literature and showed an inverse relationship between BMI and KTK performance, specifically in the WB tasks $(r=-0.21 ; p<0.05)$ and in $\mathrm{HH}(\mathrm{r}=-0.19 ; p<0.05)$. In a study carried out with children of both sexes, Lopes et al. [10] stated that, in addition to BMI, waist circumference, waist-to-height ratio and body fat percentage also showed an inverse association with KTK performance. However, in boys, higher values of waist circumference (OR $=3.296$; $95 \%$ CL 1.784; $6.090 ; p<0.001$ ) were more important to explain the low performance in KTK, regardless of the individual's aerobic fitness and mother's educational level. Such results agree with the findings of the present study, in which the waist circumference was the variable that was most associated with the task of WB $(\mathrm{r}=-0.28 ; p<0.05)$.

Vandendriessche et al. [9], in a study that also considered the isolated performance of KTK tasks, in 613 Belgian boys, including 11-year-olds, analyzed the multivariate relationships between body dimensions, biological maturation and motor coordination. In the mentioned study, the results revealed a relationship between the morphological domain (with the values of biological maturation included in this domain, also evaluated through the calculation of the maturity offset) and the performance in the KTK. The authors pointed to an inverse association between body fat measurements and the four tasks of the instrument but stated that maturation did not have a substantial effect on motor coordination. Freitas etal. [7], in a study conducted with young men and women, whose age varied between 11 and 14 years, used bone age to assess biological maturation and concluded, through multiple regression models, that the variance of the values obtained in the four KTK tasks, analyzed in isolation, is poorly explained by biological maturation. Such findings corroborate those found in the present study and raise evidence that the effect of biological maturation on the performance of $\mathrm{KTK}$, in boys, is insignificant and is perceived to be associated with body size. Still, in those studies in which the tasks of the KTKare not considered in isolation, but as strategies for obtaining the motor quotient [28, 29], this effect becomes even less substantial.

More recently, the literature has used mediation analysis models to better explain the contribution of the effect of biological maturation and growth on the motor competence of children and adolescents of both sexes, athletes [30] and non-athletes [13, 21]. In these studies, the analysis of biological maturation was performed by the somatic method of estimating adult height and, according to the results found, the most advanced maturation state contributed to optimize motor performance in physical tests of muscle strength in which there is no translocation of the total or partial body mass, in boys [30] and girls [21]. As for motor performance in motor coordination tests, the results of the present study corroborated those found by Luz et al. [13], in a study conducted with boys of prepubertal age. The waist circumference was the only anthropometric variable that mediated in the negative association between the maturational state and the WB task of the KTK. In fact, this task requires the displacement of the center of gravity in a balanced way, which can impair the performance of young people with greater fat body mass, mainly located in the waist region.

The present study contributes to the literature in that it allows a more detailed analysis of the association between biological maturation, body dimensions 
and motor coordination tasks of KTK, in young males. However, such importance does not cancel out some limitations that must be recognized. Taking into account that a cross-sectional data collection design was used and that the sample composition was made in a non-random manner, without calculating the sample size, it is not recommended to generalize the results to other individuals who do not satisfy the characteristics of the study participants. Another aspect that deserves comment is the fact that biological maturation was measured by means of a somatic method and not by bone age, although the literature shows a small effect of biological maturation in coordinative tests, regardless of the method applied to assess the maturation state.

\section{Conclusion}

The KTK has been used as a measure of gross motor coordination for various research purposes in children and adolescents with different stages of development and in multiple contexts [4]. The results of the present study showed that the maturational state has a weak association with the performance of KTK in boys with pubertal age, notably due to the inverse relationship obtained with the WB task, mediated by the accumulation of fat located in the waist region. Such findings corroborate with the literature, which has shown evidence that the maturational state, regardless of the method chosen for its assessment, seems to contribute little to the inter-individual differences found in subjects of the same sex with regard to gross motor coordination assessed by the KTK. In conclusion, it is worth mentioning that this effect may be even less noticeable when the scores obtained in the KTK tasks are not used in isolation in the analyzes, but are used to obtain the normative values, coming from the German population in which the battery was validated, for purposes calculation of the general motor quotient.

\section{References}

1. Robinson LE, Stodden DF, Barnett LM, Lopes VP, Logan SW, Rodrigues LP, et al. Motor competence and its effect on positive developmental trajectories of health. Sports Med. 2015;45(9):1273-84.
2. Stodden DF, Goodway JD, Langendorfer SJ, Roberton MA, Rudisill ME, Garcia C, et al. A developmental perspective on the role of motor skill competence in physical activity: An emergent relationship. Quest. 2008;60(2): 290-6.

3. Cools W, Martelaer KD, Samaey C, Andries C. Movement skill assessment of typically developing preschool children: a review of seven movement skill assessment tools. J Sports Sci Med. 2009;8(2):154-68.

4. Iivonen S, Sääkslahti AK, Laukkanen A. A review of studies using the Körperkoordinationstest für Kinder (KTK). Eur J Adapt. 2015;8(2):18-36.

5. Leech RM, McNaughton SA, Timperio A. The clustering of diet, physical activity and sedentary behavior in children and adolescents: A review. Int J Behav Nutr Phy. 2014;11(4):1-18.

6. Luz LG, Cumming SP, Duarte JP, Valente-dos-Santos J, Almeida MJ, Machado-Rodrigues A, et al. Independent and Combined Effects of Sex and Biological Maturation on Motor Coordination and Performance in Prepubertal Children. Perceptual Motor Skills. 2016;122(2):610-35.

7. Freitas DL, Lausen B, Maia JA, Gouveia ER, Thomis M, Lefevre J, et al. Skeletal maturation, body size, and motor coordination in youth 11-14 years. Med Sci Sports Exerc. 2016;48(6):1129-35.

8. Freitas DL, Lausen B, Maia JAR, Gouveia ER, Thomis M, Levefre J, et al. Skeletal maturation, fundamental motor skills and motor coordination in children 7-10 years. J Sports Sci. 2015;33(9):924-34.

9. Vandendriessche JB, Vandorpe B, Coelho-e-Silva MJ, Vaeyens R, Lenoir M, Lefevre J, et al. Multivariate association among morphology, fitness, and motor coordination characteristics in boys age 7 to 11. Pediatr Exerc Sci. 2011;23(4):504-20.

10. Lopes L, Santos R, Moreira C, Pereira B, Lopes VP. Sensitivity and specificity of different measures of adiposity to distinguish between low/high motor coordination. J Pediatr (Rio J). 2015;91(1):44-51.

11. D'Hondt E, Deforche B, Vaeyens R, Vandorpe B, Vandendriessche J, Pion J, et al. Gross motor coordination in relation to weight status and age in 5- to 12-year-old boys and girls: a cross-sectional study Int J Pediatr Obes. 2011;6(2-2):e556-64.

12. Malina RM, Bouchard C, Bar-Or O. Growth, maturation, and physical activity. 2nd ed. Champaign: Human Kinetics; 2004. 
13. Luz LG, Seabra A, Padez C, Duarte JP, Rebelo-Gonçalves R, Valente-dos-Santos J, et al. Waist circumference as a mediator of biological maturation effect on the motor coordination in children. Rev Paul Pediatr. 2016;34(3):352-8.

14. Harriss DJ, Atkinson G. Ethical standards in sport and exercise science research: 2016 update. Int J Sports Med. 2015;36(14):1121-4.

15. Lohman TG, Roche AF, Martorell R. Anthropometric standardization reference manual. Champaign, IL: Human Kinetics; 1988.

16. Mirwald RL, Baxter-Jones AD, Bailey DA, Beunen GP. An assessment of maturity from anthropometric measurements. Med Sci Sport Exer. 2002;34(4):689-94.

17. Drenowatz C, Eisenmann JC, Pfeiffer KA, Wickel EE, Gentile D, Walsh D. Maturity-related differences in physical activity among 10-to 12-year-old girls. Am J Hum Biol. 2010;22(1):18-22.

18. Wickel EE, Eisenmann JC. Maturity-related differences in physical activity among 13 to 14-year-old adolescents. Pediatr Exerc Sci. 2007;19(4):384-92.

19. Kiphard EJ, Schilling F. Körperkoordinationstest für Kinder - Body coordination test for children. Weinheim, Germany: Beltz Test GmbH; 1974.

20. Bigoni M, Turati M, Gandolla M, Augusti CA, Pedrocchi A, La Torre A, et al. Balance in young male soccer players: dominant versus non-dominant leg. J Sport Health Sci. 2017;13(2):253-8.

21. Luz LGO, Luz TDD, Valente-dos-Santos J, Duarte JP, Seabra A, Padez C, et al. Biological maturation and muscular strength: mediation analysis in prepubescent girls. Rev Bras Med Esporte. 2018;24(3):192-6.

22. Baron RM, Kenny DA. The moderator/mediator variable distinction in social psychological research: conceptual, strategic, and statistical considerations. J Pers Soc Psychol . 1986;51(6):1173-82.
23. Luz LGO, Coelho-e-Silva MJ, Duarte JP, Valente-dos-Santos J, Machado-Rodrigues A, Seabra A, et al. Multivariate relationships among morphology, fitness and motor coordination in prepubertal girls. J Sports Sci Med. 2018;17(2):197-204.

24. Lopes VP, Stodden DF, Rodrigues LP. Weight status is associated with cross-sectional trajectories of motor co-ordination across childhood. Child Care Hlth Dev. 2014;40(6):891-9.

25. Andrade FDS, Davidson J, Santos AMND. Comparative analysis of gross motor coordination between overweight/obese and eutrophic children. Fisioter Mov. 2020;(33):1-8.

26. D'Hondt E, Deforche B, Gentier I, Bourdeaudhuij I, Vaeyens R, Philippaerts R, et al. A longitudinal analysis of gross motor coordination in overweight and obese children versus normal-weight peers. Int J Obes (Lond). 2013;37(1):61-7.

27. Luz LGO, Teixeira e Seabra AF, Santos R, Padez C, Ferreira JP, Coelho-e-Silva MJ. Association between BMI and body coordination test for children (KTK). A meta-analysis. Rev Bras Med Esporte. 2015;21(3): 30-5.

28. Fransen J, Deprez D, Pion J, Tallir IB, D’Hondt E, Vaeyens $\mathrm{R}$, et al. Changes in physical fitness and sports participation among children with different levels of motor competence: a 2-year longitudinal study. Pediatr Exerc Sci. 2014;26(1):11-21.

29. Graf C, Koch B, Kretschmann-Kandel E, Falkowski G, Christ H, Coburger S, et al. Correlation between BMI, leisure habits and motor abilities in childhood (CHILTproject). Int J Obes Relat Metab Disord. 2004;28(1):22-6.

30. Giudicelli BB, Luz LGO, Sogut M, Massart AG, Júnior AC, Figueiredo AJ. Bio-banding in judo: the mediation role of anthropometric variables on the maturation effect. Int J Environ Res Public Health. 2020;17(1):361.

Received: 04/16/2020

Recebido: 16/04/2020

Approved: 08/04/2020

Aprovado: 04/08/2020 